\title{
Evaluation of Three Different Obturation Techniques Using Three-Dimensional Cone Beam Computed Tomography: In Vitro Study
}

\author{
Sawsan J Al Qassab ${ }^{1}$, Dunia Al Hadi ${ }^{2}$ and Alexander Maniangant Luke ${ }^{3^{*}}$ \\ ${ }^{1}$ College of Dentistry, Ajman University, Ajman, UAE \\ ${ }^{2}$ Department of Restorative Dentistry, College of Dentistry, Ajman University, Ajman, UAE \\ ${ }^{3}$ Department of Surgical Sciences, College of Dentistry, Ajman University, Ajman, UAE
}

*Corresponding author: Alexander Maniangant Luke, Department of Surgical Sciences, Assistant Professor, College of Dentistry, Ajman University, Ajman, UAE, Tel: + 00971555171094; E-mail: a.luke@ajman.ac.ae

Received date: Nov 23, 2016; Accepted date: Dec 13, 2016; Published date: Dec 20, 2016

Copyright: (c) 2016 Al Qassab SJ, et al. This is an open-access article distributed under the terms of the Creative Commons Attribution License, which permits unrestricted use, distribution, and reproduction in any medium, provided the original author and source are credited.

\begin{abstract}
Aim: The purpose of this study was to evaluate the adequacy of three different obturation techniques namely, the conventional lateral compaction, warm vertical compaction (SybronEndo, System B) and a core carrier obturation technique (DENTSPLY, GuttaCore) using three-dimensional Cone beam computed tomography (Care Stream CS 9000 3D CBCT) to measure the pulp space volume.

Materials and Methods: The study sample comprised of 30 freshly extracted human mandibular and maxillary single-root premolars which were randomly divided into three groups of 10 teeth each. Biomechanical preparation was done in all teeth using WaveOne primary reciprocating files. All three sets of teeth were imaged in Cone Beam Computed Tomography (CBCT) scanner before and after obturation. Volume of the pulp space before and after obturation were calculated using OnDemand3D software and adequacy of the obturation techniques were measured by calculating the percentage differences of the obturated volume between the groups.
\end{abstract}

Results: The data statistically analyzed using One-way ANOVA and Multiple-Range Tukey Test. There was a statistically significant difference in the obturated volume of the root canal space between the Gutta Core group and the lateral condensation group.

Conclusions: Non obturated space (voids) was seen in all three obturation techniques. GuttaCore obturators showed the greater percentage of volume (POV) of obturation followed by the system $B$ then the lateral condensation techniques.

Keywords: Cone Beam Computed Tomography (CBCT); Root canal obturation; Gutta core: Volumetric analysis

\section{Introduction}

The purposes of obturating the prepared root canal space are to eliminate all avenues of leakage from the oral cavity or the periradicular tissues into the root canal system and to seal within the system any irritants that cannot be fully removed during canal cleaning and shaping procedures.

To achieve this goal, it is believed that root canal fillings must seal the pulp space both apically and laterally to prevent further apical irritation from incomplete elimination of bacterial products or continuous communication between apical tissues and oral cavity [1].

Cold Lateral condensation with Gutta Percha is a well-recognized technique and has been the one of choice by many dental practitioners for decades. In fact, it serves as the gold standard by which we judge other techniques [2].

Recently varieties of thermo-plasticized gutta-percha obtutation methods have been introduced and numbers of studies have evaluated the apical seal achieved by these techniques. It has shown that the thermoplastic techniques have certain superiority in producing well dense gutta-percha, compared to cold techniques [3].

Core carrier obturation techniques have advantages of ease of placement and the potential for the plasticized gutta-percha to flow into the canal irregularities. Gutta core is recently developed core carrier material with no actual polysulfone carrier. It has an internal core of cross link gutta-percha which means the outer surface of the cross link gutta-percha will have alpha gutta-percha. It has been claimed that this technology allows the movement of warm guttapercha three-dimensionally into all areas of the properly shaped root canal system [4].

Traditional methods of evaluating root fillings have shortcomings and allow only partial evaluation of the root canal content. Example on sectioning the root and microscopic analysis, there could be loss of material which might mimic voids [5]. Radiographs give only twodimensional interpretations [5,6]. Dye penetration studies do not correlate clinically [7] whereas radioisotope, dye extraction, fluid filtration studies evaluate only the apical third of the tooth [8-11]. Bacterial leakage studies do not simulate exact clinical conditions, need long periods of observation and do not allow quantification of the number of penetrating bacteria [12]. 
The recently introduced three dimension computed tomography imaging techniques could be of help to overcome some of the disadvantages of the conventional methods. For example, the microCT technique have been reported to be a useful, accurate and nondestructive method for the evaluation of root canal fillings and its constituents [13]. It can also provide three-dimensional volume measurements of root canal spaces without sectioning specimens thus avoiding loss of material $[14,15]$.

Cone Beam CT $(\mathrm{CBCT})$ a relatively new extra-oral radiographic method of producing three-dimensional digital radiographic information. It has been specifically developed for imaging of the teeth and jaws. It is becoming widely available and has applications in implant dentistry, endodontic and oral surgery [16].

The aim of this study is to evaluate the adequacy of three different obturation techniques namely, the conventional lateral compaction, warm vertical compaction (SybronEndo, System B) and a core carrier obturation technique (DENTSPLY, GuttaCore), using the Cone beam computed tomography (CBCT, Care Stream S9000) imaging technique by calculating the Percentage of Obturated Volume (POV) using segmentation tool in OnDemand3D software. The null hypothesis is that there would be no significant difference in the obturated volume of the root canal space among the three different obtutation techniques.

\section{Materials and Methods}

This study was approved by the ethic committee at Ajman University of science and Technology. (Reference number: RD-2014/15-01). Seventy extracted human bicuspids with single root teeth were collected. After cleaning all teeth from the organic debris, teeth were with $5 \%$ disinfected $(\mathrm{NaOCl})$ for 10 minutes and stored in saline until use.

Digital radiographs (RVG 6100, Kodak dental systems) were acquired in bucco-lingual and mesio-distal projections for all teeth. Teeth with immature apical foramen, gross caries involving the roots, fractures and for roots with sclerosed canals, with more than one canal or those with root curvature $>10^{\circ}$ and exceptionally short roots were excluded. Out of the total (70), thirty teeth were selected and randomly distributed into three groups of ten teeth each.

\section{Access opening and canal preparation}

Oval access cavity preparation was done in all teeth using number \#4 round diamond bur through the occlusal surface. The working length was determined to be $1 \mathrm{~mm}$ short of the apical foramen using a size $10 \mathrm{~K}$-file (TG. LTD/ UK). Canal preparation was done in all teeth using the Wave One primary single file (DENTSPLY/Maillefer) size 25 and $8 \%$ taper was inserted up to the working length. After using of each instrument the canal irrigation was performed with $10 \mathrm{ml}$ of $2.5 \%$ sodium hypochlorite (DENTSPLY/Maillefer) root canals were irrigated with $5 \mathrm{ml}$ 17\%. Ethylene-Diamine-Tetra-Acetic acid (EDTA) (DENSPLY/Maillefer) and $10 \mathrm{ml}$ saline. All canals were dried with sterile paper points.

\section{Pre-obturation volume analysis of specimens with cone beam computed tomography}

A layer of putty was added around each tooth to mimic the toothsoft tissue relationship. Cone Beam Computed Tomography imaging was used to scan the teeth. Each tooth was scanned separately using care stream CS 9000 3D CBCT unit. Each image had the following parameters: Exposure values-60KV, $3.2 \mathrm{~mA}$. Voxel size- $76 \mu \mathrm{m} \times 76 \mu \mathrm{m}$ $\times 76 \mu \mathrm{m}$. Dose- $54 \mathrm{mGy} / \mathrm{cm}^{2}$ ).

CS 3D imaging software 3.4.3 (CARESTREAM HEALTH) was used for the $3 \mathrm{D}$ volumetric visualization and analysis of the image. The volume of the radicular space at the maximum width was measured by detecting the radiolucency in the canal space by OnDemand3D software (Figure 1).

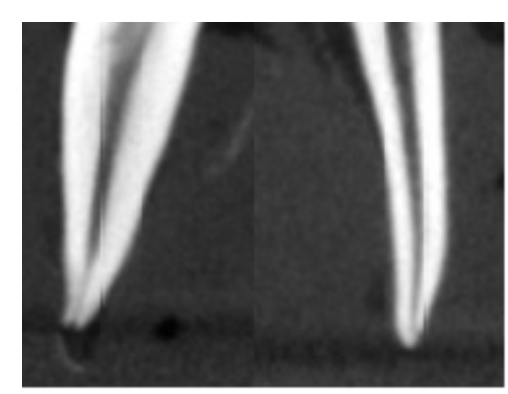

Figure 1: Canal space before obturation.

\section{Root canal obturation}

Roots were randomly divided into three experimental groups (G1, G2 and G3, N=10) that were obturated as following: All techniques by using wave one gutta-percha points (ISO 0.08) (DENTSPLY/Maillefer) matching the size of the canals prepared with wave one file.

Group 1: An ISO 0.08 matched taper gutta-percha master cone of size 25 coated with AH PLUS sealer (DENTSPLY/Maillefer) was checked for tug back at the estimated working length. Obturation was done using lateral condensation with $25,20,15$ size spreaders (DENTSPLY/Maillefer) and the respective matching accessory guttapercha cones (DENTSPLY/Maillefer).

Group 2: An ISO 0.08 matched taper gutta-percha master cone of size 25 , trimmed $0.5 \mathrm{~mm}$ short of working length. Then, select one of the System-B pluggers (Sybron Endo) that binds in the canal $6 \mathrm{~mm}$ short of the working length. Set a rubber stop at this level, and selected a conventional hand plugger (Buchanan) size 1 to fit at this length. Dry the canal with paper points. Apply a thin layer of AH26 sealer to the apical third of the master cone, and insert it to working length. Set the temperature of the System-B (Sybron Endo) at $20^{\circ} \mathrm{C}$, with full power. The tip of the plugger is placed in the center of the gutta-percha cone, heat applied and separate the plugger from the gutta-percha. It is usually found to bring with it the coronal portion of the gutta-percha and the apical part may be further compacted with conventional hand pluggers. The coronal part of the canal then obturated with injectable gutta-percha, the gutta-percha compacted in increments by hand pluggers.

Group 3: Verified the shape of the canal with a size verifier. Then, ensured 360-degree rotation at the working length. The corresponding obturator size 25 was selected. A coating of sealer AH26 was applied throughout the canal system. The Gutta core obturator (DENTSPLY/ Maillefer) heated in the oven the placed it in the canal with one continues motion. 7-10 seconds from oven to placement into the canal to full working length as per manufacturer instructions. The placement handle was removed at the orifice by bending side to side. 


\section{Post obturation volume analysis of specimens with cone beam computed tomography}

Cone Beam Computed Tomography imaging was used to scan all teeth post obturation. Each tooth was scanned separately using care stream CS 9000 3D CBCT unit. Each image had the following parameters -Exposure values $60 \mathrm{KV}, 3.2 \mathrm{~mA}$. Voxel size $76 \mu \mathrm{m} \times 76 \mu \mathrm{m}$ $\times 76 \mu \mathrm{m}$. Dose- $54 \mathrm{mGy} / \mathrm{cm}^{2}$.

CS 3D imaging software 3.4.3 (CARESTREAM HEALTH) was used for the $3 \mathrm{D}$ volumetric visualization and analysis of the image. The volume of the radicular space at the maximum width was measured by detecting the radioopacity in the canal space by OnDemand3D software (Figure 2).

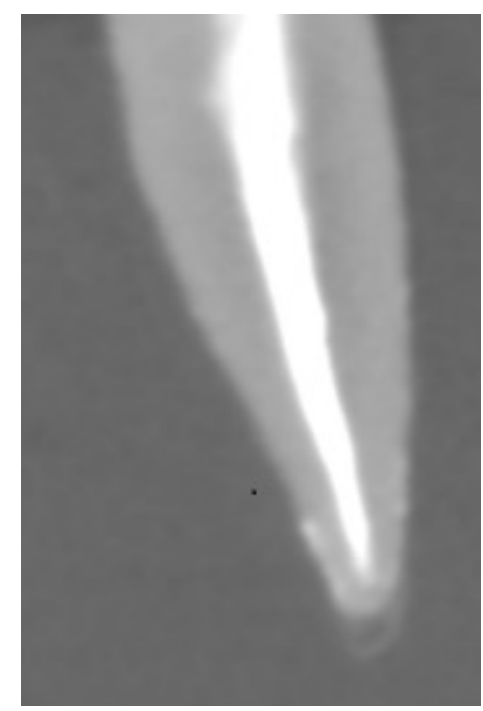

Figure 2: Canal space post obturation.

\section{Results}

The mean and standard deviation of the volume of pulp space before and after obtuation of the three different obturation techniques were calculated and their volume inadequacy determined. One-Way ANOVAs (Table 1) and Multiple-Range Tukey Test (Table 2) were used to calculate the $\mathrm{P}$ value.

\begin{tabular}{|l|l|l|l|l|}
\hline & $\mathbf{N}$ & $\begin{array}{l}\text { Mean differences } \\
\mathbf{c m}^{3}\end{array}$ & $\begin{array}{l}\text { Std. } \\
\text { deviation }\end{array}$ & $\begin{array}{l}\text { Std. } \\
\text { Error }\end{array}$ \\
\hline $\begin{array}{l}\text { Lateral Condensation } \\
(1)\end{array}$ & 10 & 0.0048 & 0.0012 & 0.0004 \\
\hline System B (2) & 10 & 0.0038 & 0.0012 & 0.0004 \\
\hline Gutta Core (3) & 10 & 0.0032 & 0.0007 & 0.0002 \\
\hline Total & 10 & 0.0039 & 0.0013 & 0.0002 \\
\hline
\end{tabular}

Table 1: ANOVA Test. Differences in Mean and Standard deviation of volume of pulp space before and after obturation.

There was a statistically significant difference between groups as determined by one-way ANOVA $(\mathrm{F}=5.8, \mathrm{p}=.008)$. A Tukey post-hoc test revealed that the volume difference was statistically significantly lower in the GuttaCore system $(.003161240,+0007369, \mathrm{p}=.006)$ as compared to the lateral condensation system. There were no statistically significant differences between Lateral condensation \& system B and between System B and GuttaCore (Table 3).

\begin{tabular}{|l|l|l|l|l|}
\hline (I) technique & (J) technique & Mean difference (I-J) & Std. error & Sig. \\
\hline \multirow{2}{*}{1} & 2 & 0.00103 & 0.0005 & 0.104 \\
\cline { 2 - 5 } & 3 & $.0016335600^{*}$ & 0.0005 & 0.006 \\
\hline \multirow{2}{*}{2} & 1 & -0.001 & 0.0005 & 0.104 \\
\hline \multirow{3}{*}{3} & 3 & 0.0006 & 0.0005 & 0.438 \\
\hline & 1 & $-.0016335600^{*}$ & 0.0005 & 0.006 \\
\cline { 2 - 5 } & 2 & -0.0006 & 0.0005 & 0.438 \\
\hline
\end{tabular}

Table 2: Tukey post-hoc test. Differences in Mean and Standard deviation of volume of pulp space before and after obturation.

\begin{tabular}{|l|l|l|l|}
\hline Sample & Mean & N & Std. Deviation \\
\hline Lateral Condensation & 92.4 & 10 & 1.57762 \\
\hline System B & 94.4291 & 10 & 1.84525 \\
\hline Gutta Core & 96.1671 & 10 & 1.02936 \\
\hline Total & 94.3321 & 30 & 2.147 \\
\hline
\end{tabular}

Table 3: Mean and Standard deviation of the Percentage of the Obturated Volume (POV)

POV=Mean volume after obturation / Mean volume before obturation $\times 100$

\section{Discussion}

Ingle and Bakland suggested that the most common cause of endodontic failures $(60 \%)$ was incomplete obturation of the root canal [1]. None of the available root canal obturation materials and techniques including the gold standard (cold lateral compaction) can produce voids free obturation. Cold lateral technique is time consuming, needs good technical skills and can increase the chances of inducing root fracture. Attempts are always made to develop efficient, easy, time saving filling techniques and increase the quality of the canal seal.

Recent advances in technology have introduced various CT machines that have been reported to be useful tools in various in vivo and laboratory studies. Compared to the traditional methods of evaluating root fillings, CT is a noninvasive technique, gives a threedimensional interpretation, avoids loss of material, and yields reproducible results; the specimens also can be used for further research.13 Recent studies have shown that three-dimensional volume measurement is possible using the spiral CT, the Micro CT $[5,13-15,17,18]$. To our knowledge our study is the first to use the CBCT for the same purpose.

The current study compares the adequacy three different root canal obturation techniques, the conventional lateral condensation, vertical compaction followed by the backfill (system B) and a new core carrier system (GuttaCore), by comparing the percentage of the obturated volume. The null hypothesis was rejected as the results showed a 
statistically significant difference in the obturated volume of the root canal space between two tested groups.

The means volume of a single adult human pulp is $0.02 \mathrm{cc}$ as put by Fanibunda [19]. Volume of the pulp space is the maximum amount of space which gutta-percha has to accommodate for hermetic seal of the canal. The root canal volume is measure before and after obturation with the help of 3D CBCT unit and an external program (on Demand $3 \mathrm{D}$ software) for more accurate mode of depiction of $3 \mathrm{D}$ volume of the obturated canals.

In current study, difference in volume (voids) were detected with in all three materials, indicating that none of the three root canal filling materials completely fills the entire canal space. The lateral condensation showed the highest inadequacy from root canal volume of prepared canal without obturation. The mean of volume difference was statistically significantly lower in the GuttaCore group $(.00316 \pm$. 000737, $\mathrm{p}=.006$ ) as compared to the lateral condensation system (. $00479 \pm .001228, \mathrm{p}=.006$ ). There were no statistically significant differences between lateral condensation group and system B group and between System B group and the GuttaCore group.

The POV was highest in the GuttaCore group (96.16714 \pm 1.02935$)$ followed by the system B group $(94.42912 \pm 1.84524)$ then the lateral condensation group (92.4000 \pm 1.57762$)$ (Table 3).

The inadequacy of cold Lateral compaction could be due to the use of spreaders during compaction, as this can lead to a greater risk of void creation between the accessory points and may leave spaces between the Gutta-percha and the dentinal walls producing less homogenous mass. The presence of voids and the inability to adapt to the walls of root canal create a less condense mass which gives difference in the measured volume calculation before and after obturation.

In accordance to our study, other studies have shown highest obturation inadequacy with the lateral condensation technique compare to thermoplacitized techniques [5,20].

Using three-dimensional spiral computed tomography, Anbu et al. [17] showed the greatest post obturation volume was obtained with System B and Thermafil techniques with no statistically significant difference between the two groups, while lateral compaction, produced significantly the least post obturation volume. A similar study [18] showed significantly higher adequacy of obturation with the core carrier obturators (Thermafil) compared to the lateral condensation when the volume of the specimens was calculated and reconstructed.

In their study, Gencoglu and Garip [21] calculated the core (guttapercha and carrier) to sealer ratio and the sealing ability of four different gutta-percha techniques and they concluded that thermafil and JS quick-fill with carrier and System B were found to be superior to the lateral condensation technique in terms of core/sealer ratio. One possible reason for Single cone Gutta core system gave the highest POV could be that the use of heat softened GP had created a better homogenous mass with less voids and better adaptation of the GP to the canal wall.

\section{Conclusion}

Within the limitations of this study, all of the three different obturation techniques showed inadequacy of obturation when the pre and post obturated volume of the root canal space were calculated. GuttaCore obturators showed the greater POV of obturation followed by the system $B$ then the lateral condensation techniques. There was a statistically significant difference in the mean difference of the obturated volume of the root canal space between the Gutta Core group and the lateral condensation group. However, no statistically significant obturated volume differences were detected between Lateral condensation \& System B or between System B and GuttaCore System.

Gutta Core obturators are simple, efficient and promising system, however, long term clinical studies are needed to evaluate the performance of those single core carrier obturators. CBCT is a useful tool for assessing root canal obturation.

\section{References}

1. Ingle J, Bakland LK (2002) Endodontics, 5th ed. BC Decker, editor. United States: Harcourt Publications pp. 576

2. Cohen S, Burns R (2000) Pathways of Pulp. 6th ed. United States: Mosby Publications: 224-225.

3. Collins J, Walker MP, Kulild J, Lee C (2006) A comparison of three guttapercha obturation techniques to replicate canal irregularities. J Endod 32: 762-765.

4. James L, Gutmann (2011) The future of root canal obturation. Dent Today 19: 1-4.

5. Asheibi F, Qualtrough AJE, Mellor A, Withers PJ, Lowe T (2014) MicroCT Evaluation of Voids in the Filling Material of Single-Rooted Teeth Obturated with Different Techniques. Journal of Research and Practice in Dentistry 14: 1-10.

6. De-Deus G, Gurgel-Filho ED, Magalhaes KM, Coutinho-FilhoT (2006) A laboratory analysis of gutta-percha-filledarea obtained using Thermafil, System B and lateral condensation. Int Endod J 39: 378-383.

7. Oliver CM, Abbott PV (2001) Correlation between clinical success and apical dye penetration. Int Endod J 34: 637-644.

8. Haïkel Y, Freymann M, Fanti V, Claisse A, Poumier F, et al. (2000) Apical microleakage of radiolabeled lysozyme over time in three techniques of root canal obturation. J Endod 26: 148-152.

9. McRobert AS, Lumley PJ (1997) An in vitro investigation of coronal leakage with three gutta-percha backfilling techniques. Int Endod J 30: 413-417.

10. Venturi $M(2006)$ Evaluation of canal filling after using two warm vertical gutta-percha compaction techniques in vivo: a preliminary study. Int Endod J 39: 538-546.

11. Kontakiotis EG, Tzanetakis GN, Loizides AL (2007) A 12-month longitudinal in vitro leakage study on a new siliconbasedroot canal filling material (gutta-flow). Oral Surg Oral Med Oral Pathol Oral Radiol Endod 103: 854-859.

12. Jacobson HL, Xia T, Baumgartner JC, Marshall JG, Beeler WJ (2002) Microbial leakage evaluation of the continuous wave of condensation. J Endod 28: 269-271.

13. Jung M, Lommel D, Klimek J (2005) The imaging of root canal obturation using micro-CT. Int Endod J 38: 617-626.

14. Nandini S, Velmurugan N, Kandaswamy D (2006) Removal efficiency of calcium hydroxide intracanal medicamentwith two calcium chelators: volumetric analysis using spiral CT, an in vitro study. J Endod 32: 1097-1101.

15. Hammad M, Qualtrough A, Silikas N (2009) Evaluation of root canal obturation: a three-dimensional in vitro study. J Endod 35: 541-544.

16. Tyndall DA, Rathore S (2008) Cone-Beam CT Diagnostic Applications: Caries, Periodontal Bone Assessment, and Endodontic Applications. Dent Clin North Am 52: 825-841.

17. Anbu R, Nandini S, Velmurugan N (2010) Volumetric analysis of root fillings using spiral computed tomography: an in vitro study. Int Endod J 43: 64-68.

18. Chokkalingam M, Ramaprabha, Kandaswamy D (2011) Threedimensional helical computed tomographic evaluation of three obturation techniques: In vitro study. J Conserv Dent 14: 273-276. 
Citation: Al Qassab SJ, Al Hadi D, Luke AM (2016) Evaluation of Three Different Obturation Techniques Using Three-Dimensional Cone Beam Computed Tomography: In Vitro Study. Dentistry 6: 403. doi:10.4172/2161-1122.1000403

Page 5 of 5

19. Bhaskar SN (1990) Orban’s Oral Histology and Embryology. 10th ed United States: CBS Publications p. 136.

20. Naseri M, Kangarlou A, Khavid A, Goodini M (2013) Evaluation of the quality of four root canal obturation techniques using micro-computed tomography. Iran Endod J 8: 89-93.
21. Gencoglu N, Garip Y, Bas M, Samani S (2002) Comparison of different gutta-percha root filling techniques: thermafil, Quick-Fill, System B and lateral condensation. Oral Surg Oral Med Oral Pathol Oral Radiol Endod 93: 333-336. 